Saifus Mujab

Naghann Bayati sebagai Alternatif Model Pembelgiaran Qur an Hadis di Madrasah

Kelas Dasar

\title{
NAGHAM BAYATI SEBAGAI ALTERNATIF \\ MODEL PEMBELAJARAN QUR'AN HADIS DI MADRASAH KELAS DASAR
}

\author{
Saiful Mujab \\ Institut Agama Islam Negeri Kudus \\ saifamujab@gmail.com
}

\begin{abstract}
ABSTRAK
Nagham bayati merupakan salah satu dari konstruksi model pelantunan lagu dalam membaca al-Qur'an. Membaca al-Qur'an selain harus menggunakan tajwid sebagai kaidah membaca(fardlu 'ain), juga dianjurkan memperindahnya dengan lagu atau nagham(sunnah). Tajwid dan nagham bayati adalah dua fakta bunyi lisan yang mampu menuangkan dan menumbuhkan rasa hingga mampu menggetarkan hati agartermotivasi untuk mempelajari, menghayati dan meresapi isi kandungan al-Qur'an. Penelitian ini mengajukan dua pertanyaan, pertama; Apakah yang dimaksud dengan nagham bayati dalam kaidah tilawah al-Qur'an?Kedua; Bagaimana implementasi nagham bayati dalam pembelajaran Qur'an Hadis? Pertanyaan tersebut menjadi pijakan dasar mengapa penelitian ini dilakukan. Hipotesa yang diajukan adalah bagaimana guru dalam mengimplementasikan nagham bayati dalam materi pembelajaran Qur'an Hadis dan pengaruh dari penerapan nagham bayati terhadap motivasi siswa dalam proses pembelajaran Qur'an Hadis. Data yang digunakan yakni data kualitatif dan audio.Data kualitatif diperoleh dari wawancara, observasi, dan peninjauan pustaka. Data audio diperoleh melalui proses perekaman. Analisis data dipaparkan secara deskriptif analisis. Sedangkan aktivitas analisis implementasi nagham bayati dikaitkan dengan proses pengolahan material pokok lagu yang menyertainya. Hasil penelitian yang diperoleh, nagham bayati adalah deretan irama atau lagu dalam tilawah al-Qur'an yang paling luas interval nadanya dan merupakan lagu induk dari ketujuh lagu pokok dalam tilawah al-Qur'an. Implementasi nagham bayati mampu meningkatkan motivasi siswa dalam mengikuti proses pembelajaran Qur'an Hadis di Madrasah.
\end{abstract}

Kata Kunci: Nagham Bayati - Alternatif - Pembelajaran Qur'an Hadis

\begin{abstract}
Nagham bayati is one of the constructs of the song singing model in reading the al-Qur'an. Reading al-Qur'an besides having to use tajwid as a reading rule (fardlu 'ain), it is also recommended to beautify it with songs or nagham (sunnah). Tajweed and nagham bayati are two facts of oral sounds that are capable of pouring out and cultivating a taste to be able to thrill the heart in order to be motivated to learn, appreciate and absorb the contents of the Qur'an. This study asks two questions, first; What is meant by nagham bayati in the rules of recitation of al-Qur'an? Second; How is the implementation of nagham bayati in learning the Qur'anic Hadith? This question becomes the basic basis for why this research was conducted. The hypothesis proposed is how the teacher implements
\end{abstract}

MUBTADI: Jurnal Pendidikan Ibtidaiyah

Vol. 2 No. 2, Januari - Juni 2021

$P$ - ISSN : 2715 - 7067

E - ISSN : 2720 - 8850 
nagham bayati in the Qur'anic Hadith learning material and the influence of the application of nagham bayati on student motivation in the learning process of the Qur'anic Hadith. The data used were qualitative and audio data. Qualitative data were obtained from interviews, observations, and literature reviews. Audio data is obtained through the recording process. The data analysis was presented descriptively. Meanwhile, the analysis of the implementation of Nagham Bayati is related to the processing of the main material for the accompanying songs. The result of this research shows that nagham bayati is a series of rhythms or songs in the recitations of the Qur'an with the widest range of notes and is the main song of the seven main songs in the recitation of the Qur'an. The implementation of nagham bayati can increase students' motivation in participating in the learning process of the Qur'anic Hadith in Madrasah.

Keywords: Nagham Bayati - Alternative - Learning the Qur'an, Hadith

\title{
PENDAHULUAN
}

Qur'an Hadis merupakan salah satu dari empat mata pelajaran Pendidikan Agama Islam yang ada di Madrasah ${ }^{1}$. Mata Pelajaran ini telah menjadi ciri khas dan karakter dari pembelajaran di madrasah, menjadi pembeda antara madrasah dan sekolah, dan juga menjadi tolak ukur keberhasilan penanaman karakter dan sikap para lulusan dari madrasah.

Kebijakan pemerintah tentang ujian Nasional ternyata memberi pengaruh terhadap animo peserta didik terhadap keberadaan mata pelajara agama Islam.Adanya Ujian Nasional memang membawa dampak positif terhadap keberadaan dan eksistensi pendidikan madrasah, pengakuan dan kesetaraan dengan sekolah adalah bukti nyata. Namun, disela-sela dampak positif ujian Nasional terhadap madrasah, terdapat fenomena menarik yang layak untuk kita cermati, yaitu menurunnya stigma, trend, animo atau standar mata pelajaran agama Islam dalam paradigma peserta didik di madrasah.

Kita semua tahu, bahwa mata pelajaran di madrasah yang diujikan di dalam Ujian Nasional adalah mata pelajaran Bahasa Indonesia, Ilmu Alam, Ilmu Sosial, Kewarganegaraan dan Matematika untuk Madrasah Ibtidaiyyah. Hal ini bedampak pada pola fikir atau stigma terhadap mata pelajaran yang tidak diujikan secara nasional.Qur'an

\footnotetext{
${ }^{1}$ Mata Pelajaran Pendidikan Agama di Madrasah yaitu Qur'an Hadis, Akidah Akhlak, Fiqih dan Sejarah Kebudayaan Islam
}

\author{
MUBTADI: Jurnal Pendidikan Ibtidaiyah \\ Vol. 2 No. 2, Januari - Juni 2021 \\ P - ISSN : $2715-7067$ \\ E - ISSN : $2720-8850$
}


Hadis contohnya, sebagai mata pelajaran Pendidikan Agama Islam ini akhirnya turun kasta dalam pandangan peserta didik menjadi mata pelajaran kualifikasi kedua, bahkan ketiga.Sebagian besar guru, peserta didik bahkan madrasah pun sepakat bahwa mata pelajaran yang di-UN-kanlah yang harus dinomersatukan, dan yang harus disukseskan. Bahkan, demi sukses ujian nasional, madrasah harus menambah jam pelajaran, madrasah harus beruji coba berulang-ulang, dan demi ujian nasional peserta didik rela manjalani bimbingan belajar diluar program madrasah.

Dengan fenomena seperti ini, muncullah pertanyaan, bagaimanakah menjadikan peserta didik agar tetap semangat dan mempunyai motivasi tinggi dalam mengikuti mata pelajaran non ujian nasional?

Qur'an Hadis, salah satu mata pelajaran non ujian nasional yang terkena dampak "penurunan kasta" di mata peserta didik dalam realitanya, dari pengamatan awal peneliti di beberapa madrasah di kabupaten Kudus, memunculkan stigma bahwa mata pelajaran Qur'an Hadis benar-benar telah di"nomordua"kan, bahkan sekedar pelengkap dalam pembelajaran di beberapa madrasah. Hal ini sangat ironis, mengingat ciri khas madrasah, tujuan utama pendidikan agama Islam di madrasah adalah mengerti, memahami dan menjalankan al-Qur'an dan al-Hadits.

Melihat fenomena seperti ini beberapa madrasah lewat para guru telah berupaya agar peserta didik selalu termotivasi untuk belajar Qur'an Hadis. Para guru Qur'an Hadis telah melakukan berbagai strategi agar mata pelajaran Qur'an Hadis di"idola"kan dan digemari peserta didik. Berbagai upaya dan metode pembelajaran dari para guru telah diterapkan.Salah satu metode yang menarik dari pengamatan awal yang diterapkan adalah metode tilawah atau di biasa disebut dengan seni baca al-Qur'an.Metode ini memiliki tiga tahapan pembalajaran, yaitu tahap identifikasi hukum bacaan (ilmu tajwid), praktek bacaan (fashahah, makharijul huruf, adabut tilawah) serta penerapan lagu-lagu tilawah (ilmu nagham).

Penerapan metode tilawah dalam pembelajaran mata pelajaran Qur'an Hadis memang tergolong langka dan jarang sekali diterapkan, karena metode ini membutuhkan skill, bakat dan kompetensi khusus yang harus dimiliki oleh setiap guru pengampu Qur'an Hadis. Pada metodeini, selain mengharuskan guru bisa dan mampu membaca al-Qur'an dengan baik dan benar (fasih) sesuai dengan kaidah ilmu tajwid, guru juga diharuskan mampu melafalkan ayat-ayat al-Qur'an dengan berbagai macam lagu-lagu tilawah (nagham) secara mujawwad.

Dari hasil pengamatan dan wawancara penulis dibeberapa madrasah di Kabupaten Kudus, diperoleh keterangan bahwa terdapat beberapa guru yang mempunyai keilmuan 
tentang tilawah dan menggunakan metode nagham ini dalam sebuah pembelajaran Qur'an Hadis, diantaranya adalah guru di MTs Assalam Kudus. Menurut Ustadz Ali Ahsan, salah satu guru Qur'an Hadis, metode tilawah ini diterapkan agar siswa termotivasi untuk lebih menyukai dan termotivasi belajar Qur'an Hadis, yang selama ini terkuras konsentrasinya dalam berbagai persiapan Ujian Nasional (UN), dimana UN yang tanpa mengujikan mata pelajara Qur'an Hadis. ${ }^{2}$ Selain itu juga ustadz Sholihul Hadi di MTs Nurul Huda Kaliwungu juga menerapkan hal yang sama, menerapkan metode tilawah dengan Nagham Bayati sebagai model pembelajarannya. ${ }^{3}$

Dengan penerapan metode tilawah khususnya dengan nagham bayati ini dimaksudkan agar siswa benar-benar bisa membaca al-Qur'an dengan baik dan benar sesuai ilmu tajwid, dan disertai dengan lagu yang indah untuk didengarkan sesuai dengan kaidah nagham, sehingga akan menambah motivasi siswa dalam membaca, mempelajari, memahami dan mengamalkan al-Qur'an.

Maka, berdasarkan latar belakang diatas, penulis tertarik untuk meneliti bagaimana sebenarnya penerapan model pembelajaran tilawahdengan nagham bayati di madrasah benar-benar efektif, apakah penerapan nagham bayati mempunyai dampak positif terhadap keaktifan dan motivasi siswa dalam mengikuti proses pembelajaranpada mata pelajaran Qur'an Hadis.

\title{
PEMBAHASAN
}

1. Pengertian dan Sejarah Perkembangan Nagham Bayati

Naghamsecara etimologi adalah irama atau lagu yang dipakai dalam seni baca AlQur'an.Jamak dari lafadz nagham adalah naghamaat yang berarti rangkaian beberapa irama dan lagudalam melantunkan ayat al-Qur'an. Irama dalam hal ini adalah irama yang biasa dipakai adalah irama Arab (Naghamat Arabiyyah) atau yang terkenal dengan irama Padang Pasir. $^{4}$

Sedangkan bayati adalah salah satu jenis dari nagham. Secara etimologi bayati dari kata baityang berarti rumah, induk, utama atau pokok. Jadi nagham bayati adalah lagu utama dalam tilawah al-Qur'an.

\footnotetext{
${ }^{2}$ Hasil wawancara penulis dengan Ustadz Ali Ahsan pada tanggal 17 Februari 2018 di Madrasah Tsanawiyyah Assalam Tanjungkarang Kudus

${ }^{3}$ Hasil wawancara dengan Ustadz Sholihul Hadi, guru Qur'an Hadis di MTs Nurul Huda Kaliwungu Kudus pada tanggal 20 februari 2018

${ }^{4}$ Mujab, Saiful, Ilmu Ngham, Kaidah Seni Baca al-Qur'an, 2011, hal. 7
}

\author{
MUBTADI: Jurnal Pendidikan Ibtidaiyah \\ Vol. 2 No. 2, Januari - Juni 2021 \\ $P$ - ISSN : 2715 - 7067 \\ E - ISSN : $2720-8850$
}


Dalam sejarah,tumbuh dan berkembangnya lagu-lagu al- Qur'an terlihat adanya dua jenis aliran lagu yang berbeda, yaitu :

a. Naghamat Makkawi, yaitu lagu-lagu yang tumbuh dan berkembang di Makkah dan sekitarnya (Jazirah Arabbagiantimur). Lagu-lagunya menggambarkan suatu dialek bahasa lingkungan tersebut. Di Indonesia dibawakan oleh Qari-Qari periode terdahulu. Kemudian dikenalkan beberapa nama lagu dari aliran tersebut seperti misalnya lagu Hijaz, Mayya, Raqby, Banjaka dan lain-lain.

b. Naghamaat Mishri,ini adalah lagu-lagu Arab ala Mesir yang tumbuh dengan subur di lembah sungai Nil. Lagu-lagu tersebut lebih lembut, syahdu sesuai degan dialek lembah Nil itu sendiri. Dan lagu-lagu ala Mesir ini nampaknya jauh lebih dominan, diterima dan berkembang cepat di seluruh dunia Islam, termasuk Indonesia. Di Indonesia sendiri, ternyata hampir dapat dipastikan, bahwa kebanyakan orang membaca al-Qur'an dengan lagu-lagu ala Mesir. Baik membaca al-Qur'an dalam acara atau haflah, bahkan dalamMusabaqah Tilawatil Qur'an hampir semuanya lagu Mishri dan jarang sekali menggunakan lagu-lagu Makkawi kecuali hanya sebagai variasi saja.

Lagu- lagu Al- Qur'an sendiri yang biasa dikenal dengan sebutan naghamat atau naghamat, dibedakan menjadi 3 bagian, di antaranya :

a. Naghamat Ashliyyah

Dalam Naghamat Ashliyyah terdapat 7 macam lagu, di sisi lain ada yang menyebut 8 macam lagu di antaranya yang terhimpun dalam ungkapan :

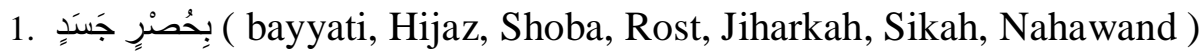

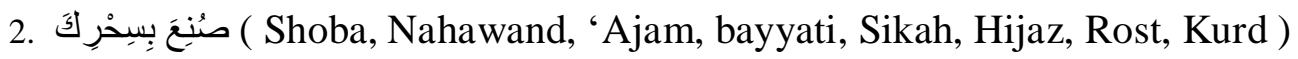

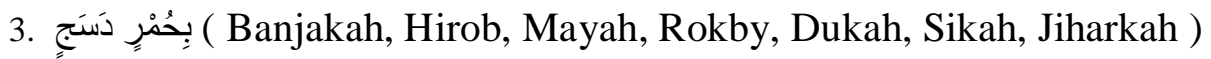

b. Naghamat Far'iyyah

Naghamat Far'iyyah merupakan cabang lagu dari naghamat ashliyyah, di antaranya

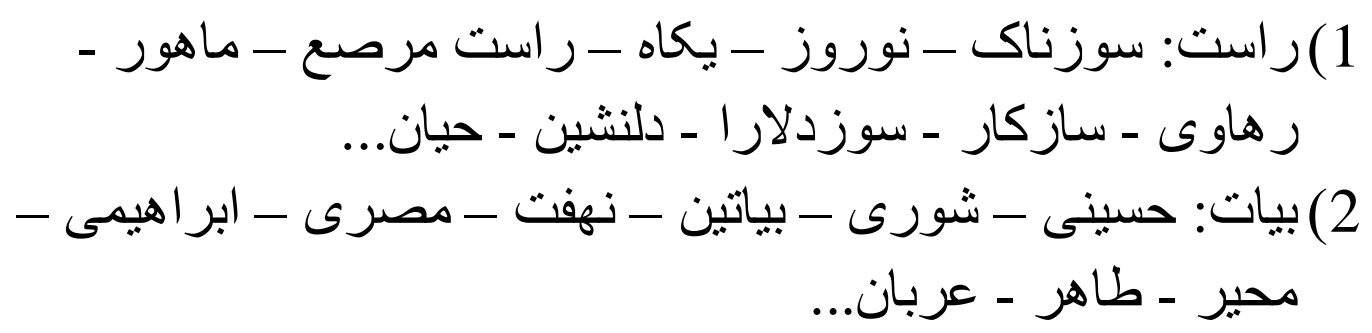




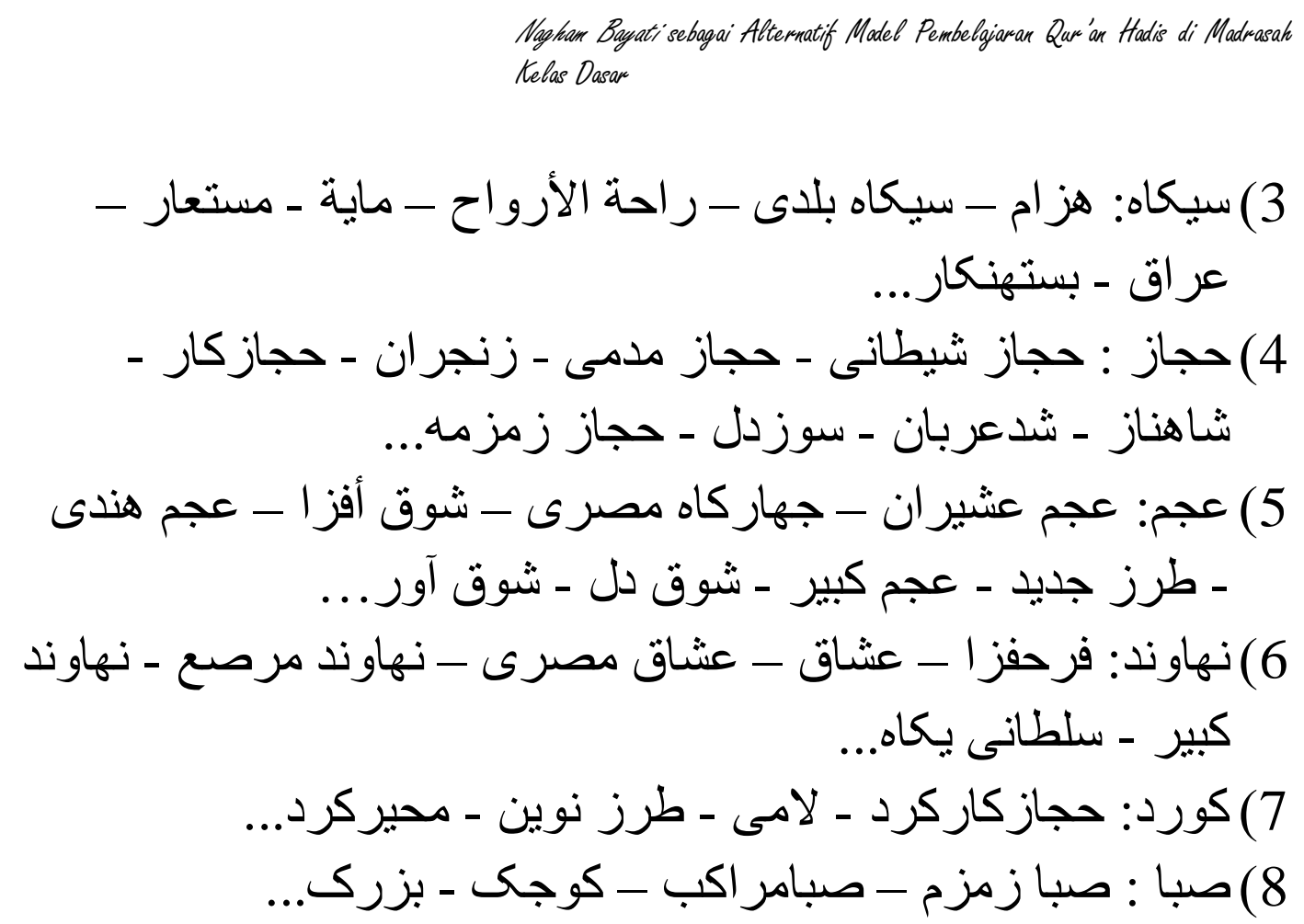

c. Naghamat Murokkabah

Naghamat murokkabah merupakan perpaduan antara beberapa nagham, misal : shoba ma'al 'ajam, bayyati ma'a rost, hijaz ma'al bayyati, maqom hakimi ( gabungan maqom bayyati dan shoba ) dan lain sebagainya.Dalampemaparan kali inihanya peneliti hanya menyampaikan nagham atau lagu-lagual-Qur'anala Misri, khususnya pada nagham bayati yang menjadi kajian penelitian agar lebih focus dalam pembahasan.

Dari aliran misri ini munculah tujuh macam lagusangatpopulersaatini, yang biasa dinyatakandalam singkatan״ِحُْصْرِ جَسَدِ. Yakni; bayati, hijaz, shoba, rast, jiharkah, sikaah dan nahawand.

Secara teoritis, nagham bayati mempunyai ciri khusus, yakni lembut meliuk-liuk memiliki gerak lambat (Adagio) dengan pergeseran nada tajam waktu turun naik dan yang seringkali terjadi secara beruntun. Bayyati memiliki ruang lingkup yang luas, fleksibel setara mudah diterima. Manakala nagham bayyati ini sudah dikombinasikan dengan syuri misalnya, maka ia akan nampak lebih hidup, lebih dinamis karena corak iramanya yang meliuk-liuk, menarik-narik tajam.

Dalam satu pendapat, mengatakan bahwa kata bayati berasal dari bahasa Arab, bait yang berarti rumah, kemudian digunakan dalam bentuk mubalaghah menjadi bayyat.

\section{MUBTADI: Jurnal Pendidikan Ibtidaiyah}

Vol. 2 No. 2, Januari - Juni 2021

$P$ - ISSN : 2715 - 7067

E - ISSN : $2720-8850$ 
Mubalaghah adalah bentuk kata yang berfungsi untuk menyangatkan atau melebihlebihkan.Jadi bayati adalah jenis lagu dalam tilawah yang iramanya sangat tajam, merdu dan syahdu. ${ }^{5}$

Bahkan lagu bayati ini, karena sifatnyayang luwes, ruang lingkup iramanya yang luas, ia sering dianggap orang sebagai lagu induk.Sebutan itu ada benarnya, karena pada umumnya seseorang akan merasa lebih mudah pindah-pindah kepada lagu apa saja, setelah melewati lagu bayyati terlebih dahulu, seolah-olah bayyati telah mengundang unsur-unsur irama lagu yang lain. Dengan kata lain, bayyati adalah satu-satunya nagham lagu yang paling dekat dengan seluruh lagu yang ada (6 pokok lagu yang lain).

Karakter lagu bayati cenderung nada rendah-naik-dan makin naik berkarak ternetral tidak riang atau tidak terlalu sedih, Maka banyak juga dipakai untuk melantunkan lagulagu kosidah, sholawat, bacaan sholat, dzikir dan sebagainya..

Disamping itu, juga telahmenjadi kenyataan bahwa, nagham bayati telah dipergunakan oleh sebagian besar qari-qariah sebagai pangkal titik tolak, dan tempat kembalinya suatu komposisi lagu. Dengan demikian, betulah anggapan yang mengatakan bahwa nagham bayyati merupakan nagham lagu yang sangat luas, seakan-akan ia adalah induk semang dari seluruh lagu yang ada.

Naghambayati pada umumnya dipergunakan orang sebagai lagu pertama (pembuka) dan juga dipakai sebagai lagu penutup (quflah). Namun demikian tidak menutup kemungkinan bahwa seorang qari' boleh saja bebas memilih untuk memulai dengan lagu pilihannya, dan menutup tanpa dengan lagu bayyati.

DalamperaturanMusabaqah Tilawatil Qur'an (MTQ) Nasionalpada babak semifinal,seorangqari' wajib membawakan lagu Bayyati sebagai lagu pertama, sekaligus dengan tiga hingga empat tingkatantangganadanya, yaitu nada qarar (rendah), nada nawa (sedang), nada jawab (tinggi) dan nada jawabul jawab (paling tinggi/tertinggi).Maka, kalaulaguBayyati ini dipakai pada awal komposisi, maka ia akan mengalami proses tahapan-tahapan sesuai dengan tingkatan nadadan jenis cabang yang dilampui sebagai berikut ${ }^{6}$ :

1. BayyatiAshli Qarar (Lagu Bayati dengan jenis Ashli dan bernada rendah)

${ }^{5}$ Bimas Islam, Pedoman Pelatihan Tilawatil Qur'an, Jakarta, 1995, hal. 109

${ }^{6}$ Mujab Saiful, Ilmu Nagam, Kaidah Seni Baca al-Qur'an, Kudus, 2011, hal 36 
2. BayyatiAshli Nawa (Lagu Bayati dengan jenis Ashli dan bernada sedang)

3. Bayyati Syuri Nawa (Lagu Bayati dengan jenis Syuri dan bernada sedang)

4. Bayyati Husaini Nawa (Lagu Bayati dengan jenis Husaini dan bernada sedang)

5. BayyatiAsli Jawab (Lagu Bayati dengan jenis Ashli dan bernada tinggi)

6. BayyatiAsli Jawabul Jawab (Lagu bayati dengan jenis Asli dan bernada paling tinggi)

7. Bayyati Syuri Jawabul Jawab (Lagu Bayati dengan jenis Syuri dan bernada Paling Tinggi)

Adapun rumus atau standar lagu, irama dan gaya dalam seni baca al-Qur'an biasa disebut dengan tausyih. Dengan kata lain, tausyih merupakan wazan an-nagham yang menjadi acuan penerapan, atau rumus irama dan nada suatu lagu tilawah. Tausyikh nagham bayyati secara lengkap dapat kita lihat di bawah ini :

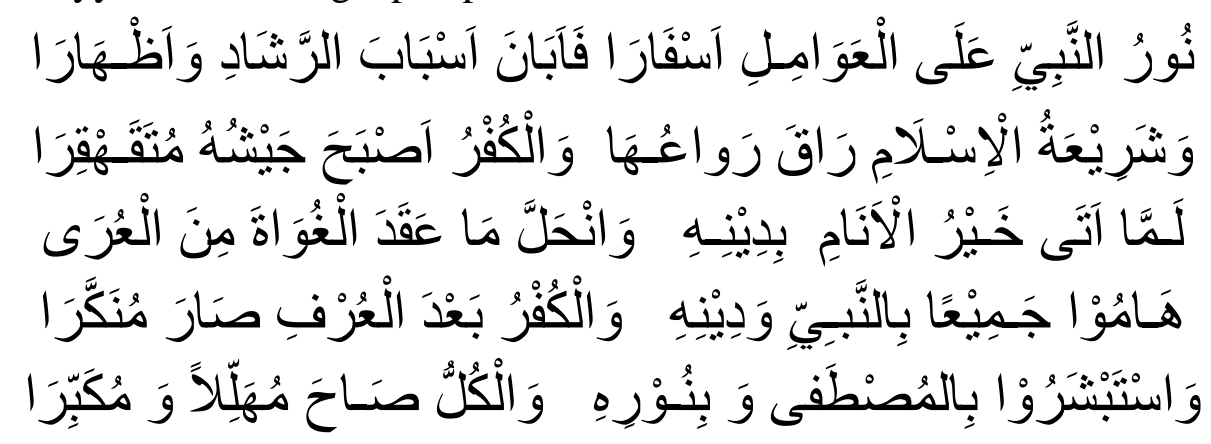

Untuk memudahkan pembelajaran tausyih diatas, para qari biasanya belajar secara musyafahah atau bertemu langsung antara pengajar dan peserta didik agar bisa menerapkan metode taqrir/mudzakarah atau pengulangan. Untuk memudahkan hafalan lagu juga bisa menggunakan sistem voice recorder atau alat perekam sebagai pengingat nada dan bisa diulang kapan dan dimanapun.

2. Penerapan Nagham Bayatidalam Pembelajaran Qur'an Hadis

- Pembelajaran Qur'an Hadis

Bidang studi Qur'an dan Hadis merupakan unsur mata pelajaran Pendidikan Agama Islam (PAI) di madrasah yang memberikan pemahaman kepada peserta didik tentang al Qur'an dan al Hadits sebagai sumber ajaran agama Islam.Bidang studi Qur'an Hadis, secara substansial memiliki konstribusi dalam memberikan motivasi kepada peserta didik 
untuk memahami dan mempraktekkan nilai-nilai keyakinan keagamaan yang bersumberkan pada al Qur'an dan al Hadits dalam bentuk akhlak al-karimah dalam kehidupan sehari-hari.Oleh karena itu, bidang studi Qur'an Hadis tidak hanya mengantarkan peserta didik untuk menguasai berbagai macam pengetahuan tentang al Qur'an dan al Hadits, tetapi yang terpenting adalah bagaimana peserta didik dapat mengamalkan ajaran-ajaran itu dalam kehidupan sehari-hari.Maka, implikasinya dalam proses pembelajarannya harus menekankan keutuhan dan keterpaduan anatara ranah kognitif, ranah afektif (minat, sikap, moral, nilai-nilai yang bersumber pada al Qur'an dan al Hadits) dan ranah psikomotorik (ketrampilan motorik yang dilakukan atas dasar kesadaran rohaniahnya).

Dalam buku panduan kurikulum bidang studi Qur'an Hadis Departemen Agama (2004: 2), karakteristik bidang studi Qur'an Hadis di Madrasah ada dua, yaitu :

a. Menerapkan ilmu tajwid dalam bacaan al Qur'an.

b. Memahami dan mengamalkan isi kandungan al Qur'an dan al Hadits dalam kehidupan sehari-hari.

Secara fungsional mata pelajaran ala Qur'an dan al Hadits memiliki fungsi sebagai berikut:

1) Pengajaran, yaitu penyampaian imu pengetahuan terutama dari kandungan al Qur'an dan al Hadits, yang selanjutnya melandasi sikap dan keyakinan untuk dipraktekkan dalam kehidupan sehari-hari.

2) Sumber nilai yaitu pengajaran al Qur'an dan al Hadits yang dapat memberikan kesadaran untuk mempedomaninya untuk mencapai kebahagiaan dunia dan akhirat.

3) Sumber motivasi, yaitu membrikan dorongan untuk meningkatkan prestasi dan kuallitas hidup beragama, bermasyarakat dan bernegara.

4) Pengembangan, yaitu meningkatkan kemempuan peserta didik dalam memahami isi dan kandungan al Qur'an dan al Hadits dan menumbuh kembangkan lebih lanjut dalam diri peserta didik melalui proses pendidikan agar kemampuan dan pemahaman tersebut dapat berkembang secara optimal sesuai dengan tingkat perkembangannya.

5) Perbaikan, yaitu memperbaiki kesalahan-kesalahan dalam memahami dan mengamalkan isi dan kandungan al Qur'an dan al Hadits dalam kehidupan seharihari. 
6) Pencegahan, yaitu untuk menangkal hal-hal negatif dari lingkungan atau budaya lain yang dapat membahayakan diri peserta didik dan menghambat perkembangannya menuju manusia yang beriman dan bertakwa.

7) Pembiasaan, yaitu menyampaikan pengetahuan, pendidikan dan penanaman nilainilai al Qur'an dan al Hadits kepada peserta didik, dalam konteks lingkungan fisik maupun sosialnya sesuai dengan tuntunan al Qur'an dan al Hadits.

Pada penelitian kali ini, materi pembelajaran al-Qur'an Hadis di Madrasah pada semester genap bertepatan dengan sebuah tema materi "Kunikmati Al-Qur'an dengan Tajwid dengan subbab Ilmu Tajwid dan sifat Huruf Hijaiyah", dengan Kompetensi Inti sebagai berikut ${ }^{7}$ :

- Menghargai dan menghayati ajaran agama yang dianutnya.

- Menghargai,danmenghayatiperilakujujur,disiplin,tanggungjawab,peduli (toleransi, gotong royong), santun, percaya diri, dalam berinteraksi secara efektif dengan lingkungan sosial dan alam dalam jangkauan pergaulan dan keberadaannya.

- Memahamipengetahuan(faktual,konseptual,danprosedural) berdasarkan rasa ingintahunyatentangilmupengetahuan,teknologi,senibudayaterkaitfenomena dan kejadian tampak mata.

- Mengolah, menyaji dan menallar dalam ranah konkret (menggunakan, mengurai, merangkai, memodifikasi, dan membuat) dan ranah abstrak (menulis, membaca, menghitung, menggambar, dan mengarang) sesuai dengan yang dipelajari di sekolah dan sumber lain yang sama dalam sudut pandang/teori.

Adapun kompetensi dasarnya adalah menerapkan hukum bacaan idgham bighunnah dan bilaghunnah dalam Q.S. al-zalzalah,al-Masad, dan Qur'an surat-surat pendek pilihan.

- Langkah-langkah Penerapan Nagham Bayati

Selanjutnya, langkah-langkah implementasi model pembelajaran nagham bayati pada pembelajaran Qur'an Hadis adalah sebagai berikutyaitu':

1) Guru membacakan ayat atau surat dengan memberi contoh terlebihbacaan yang baik dan benar sesuai kaidah tajwid dan ilmu nagham terlebih dahulu.

\footnotetext{
${ }^{7}$ Departemen Agama, Silabi dan Materi Qur'an Hadis Untuk Madrasah Tsanawiyah, 2004

${ }^{8}$ Hasil Pengamatan dan wawancara penulis pada bulan Maret 2018 di Madrasah Tsanawiyah Assalam Kudus dan Madsrasah Tsanawiyah Nurul Huda Kaliwungu Kudus.
}

\section{MUBTADI: Jurnal Pendidikan Ibtidaiyah \\ Vol. 2 No. 2, Januari - Juni 2021 \\ $P$ - ISSN : $2715-7067$ \\ E - ISSN : $2720-8850$}


2) Guru mengidentifikasi bacaan sesuai kaidah tajawid yang terdapat pada ayat dan menjelaskan jenis lagu yang diterapkan.

3) Peserta didik mengikuti bacaan guru secara bersama-sama sampai benar-benar dianggap mampu membaca.

4) Guru kemudian menunjuk salah satu atau beberapa peserta didik untuk membaca secara individu untuk mengetahui hasilnya.

5) Guru mengevaluasi bacaan setiap peserta didik dan membenarkannnya

Berdasarkan hasil observasi yang peneliti lakukan, bahwa pada saat guru memberi contoh bacaan ayat yang menggunakan tilawah nagham bayati telah sesuai dengan kaidah-kaidah nagham bayati. Berikut ini penerapannya :

\begin{tabular}{|c|c|c|}
\hline No & Jenis Bayati\& Nada & Ayat \\
\hline 1 & Ashli Qarar & اذا زلزلة الأرض زلز الها \\
\hline 2 & Ashli Nawa & واخرجت الأؤض أثقالها \\
\hline 3 & Syuri Nawa & وقال الإنسان مالها \\
\hline 4 & Husaini Nawa & يومئذ تحدث أخبار ها \\
\hline 5 & Ashli Jawab & بأن ربك اوحى لها \\
\hline 6 & Ashli Jawabul Jawab & يومئذ يصدر الناس اثتاتا ليرو أعمالهح \\
\hline 7 & Syuri Jawabul Jawab & فمن يعمل مثتال ذرة خير ا يره \\
\hline 8 & Quflah & ومن يعمل مثقال ذرة شر ا يره \\
\hline
\end{tabular}

Pada saat guru menggunakan metode tilawah Nagham Bayati pada pembelajaran al-Qur'an hadis, ada beberapa anak merasakan ada sesuatu yang baru yang membuat mereka bersemangat. Berbeda dengan pembelajaran sebelumnya, ketika membaca al-Qur'an tidak mengikuti lagu atau nagham. Apalagi bagi siswa yang sudah pernah bisa atau baru belajar tentang metode tilawah.

Meskipun demikian, pada pertemuan pertama ini, masih banyak siswa yang kurang bersemangat dan tidak percaya diri dengan bacaanya. Hal ini terlihat saat guru menyuruh beberapa siswa untuk mencoba bacaannya, terdapat siswa yang masih belum berani dan takut mencobanya. Untuk mengatasi masalah tersebut, pada pertemuan yang 
awal ini, guru meminta siswa untuk mempraktekkan secara bersama-sama atau berkelompok, karena dengan berkelompok, para siswa memungkinkan untuk lebih berani dalam mempraktekkan bacaannya.

Memang jika diamati secara seksama, siswa sebenarnya telah menguasai secara kognitif, namun dalam psikomotorik dengan melagukan ayat al-Qur'an masih perlu dilatih terus menerus. Akan tetapi, dengan waktu yang relatif baru dan singkat ternyata penerapan Nagham Bayati dalam pembelajaran al-Qur'an telah mampu merubah suasana pembelajaran al-Qur'an Hadis. Terlihat dari semangat, rasa untuk bisa, dan rasa suka siswa dalam sebuah pembelajaran.

Pembelajaran awal ini hanya dilakukan sampai pada ayat 4 atau nagham bayati husaini, mengingat waktu yang dibutuhkan dalam pembelajaran dengan metode ini sangat banyak karena butuh pengulangan sesering mungkin agar lagu-lagu dapat menempel pada memori siswa. Maka, pendidik harus dapat mengatur, menghemat dan meng-efisienkan waktu pembelajaran sebaik mungkin.

Pada pertemuan kedua, guru mengulang pembelajaran sebelumnya yaitu membaca ayat 1-4 terlebih dahulu kemudian melanjutkan ayat 5 dan seterusnya. Cara yang dilakukan untuk melanjutkan pembelajaran ayat berikutnya tidak berbeda pada ayat sebelumnya yaitu membaca surat al-Zalzalah dengan nagham bayati; yaitu guru membaca ayat terlebih dahulu untuk memberikan contoh, kemudian peserta didik mengikuti bacaan guru secara bersama-sama, sampai dengan benar-benar dianggap mampu dan menguasai. Selanjutnya, guru mempersilahkan salah satu atau beberapa peserta didik untuk membaca secara individu agar dapat diketahui hasilnya.

Berdasarkan catatan peneliti, peserta didik mulai terlihat antusias dalam mengikuti pembelajaran. Bahkan sudah mulai ada yang berani menyalahkan bacaan dan lagu temannya. Tetapi masih ada anak yang kurang bersemangat walaupun sedikit, yang kemungkinan saja masih ada rasa takut dan malu kalau disuruh mencoba dan mengulangi bacaan.Pembelajaran yang kedua ini dapat menyelesaikan sampai ayat terakhir atau nagham bayati quflah. Peneliti masih berpendapat bahwa metode ini butuh waktu yang lebih efisien dalam pengajarannya. Atau pendidik hendaknya lebih berhemat waktu dalam pembelajarannya.

Pada pertemuan berikutnya, Kompetensi Inti dan Kompetensi dasarnya masih sama, hanya materinya bacaannya ganti surat al-Masad. Pada pelaksanaan pembelajaran tersebut tidak ada perubahan dengan pembelajaran sebelumnya. Langkah-langkahnya yaitu : 
Langkah awal : mengidentifikasi dan membaca bacaan qalqalah pada surat alMasad dengan mengurai huruf demi huruf.

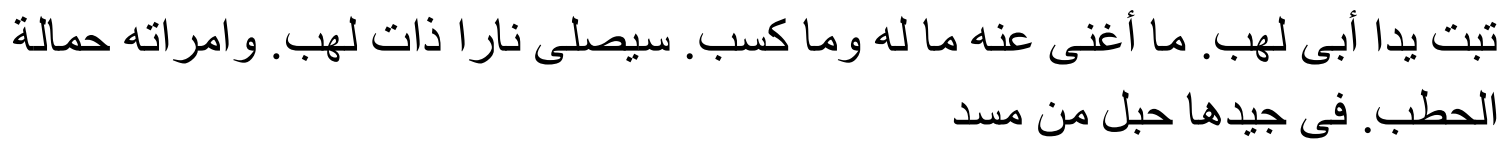

Langkah inti :

1. Mengidentifikasi huruf-huruf qalqalah dan cara membacanya

2. Membaca surat al-Masad denan nagham bayati; yaitu guru membaca terlebih dahulu, dilanjutkan peserta didik membaca dengan bersama-sama, sampai dengan benar-benar dianggap mampu.

3. Setelah bersama-sama, guru mempersilahkan salah satu atau beberapa siswa untuk membaca secara individu untuk mengetahui hasilnya.

4. Mengidentifikasi kendala pembelajaran agar bisa teratasi.

Langkah akhir :

1. Mengulangi kembali pembelajaran dari awal, agar siswa semakin faham dan mengingat dengan baik.

\begin{tabular}{|c|c|c|c|}
\hline No & MAQAM (NADA) & JENIS BAYATI & AYAT \\
\hline 1 & Jawab & Ashli & تبتث بدا أبى لهب \\
\hline 2 & Jawab & Syuri & ما أغنى عنه ما لله وما \\
\hline 3 & Jawabul jawab & Syuri & 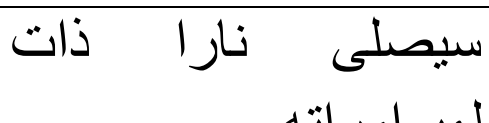 \\
\hline 4 & Quflah & Ashli & حمالة الحطب \\
\hline 5 & Quflah & Ashli & فى جيدها حبل من مسد \\
\hline
\end{tabular}

3. Analisa Hasil Penelitian 
Berdasarkan observasi yang dilakukan peneliti, pembelajaran Qur'an Hadis di madrasah memang dibutuhkan sebuah strategi alternatif agar minat peserta didik meningkat. Faktor Ujian Nasional yang tidak menyertakan mata pelajaran Qur'an Hadis sebagai mapel yang diujikan memang sangat berpengaruh terhadap motivasi siswa dalampembelajaran. Ini diketahui dari pengamatan dan wawancara terhadap beberapa siswa.

Penggunaan metode alternatif dengan menggunakan Metode Tilawah khususnya dengan Nagham Bayati diharapkan mampu meningkatkan motivasi siswa dalam mengikuti pembelajaran. Penerapan metode ini awalnya terlihat biasa saja, yaitu dengan membaca alQur'an dengan disertai lagu. Namun ternyata terdapat nama-nama lagu, tingkatan nada dan fariasi yang harus dimengerti peserta didik, menjadikan rasa ingin bisa melagukan alQur'an dan ingin tahu terhadap nada-nada al-Qur'an dalam ilmu nagham.

Dalam setiap pertemuan penulis mencatat pada awal pertemuan peserta didik terlihat pasif sekedar menikmati dan mendengarkan bacaan, namun pada pertemuanpertemuan berikutnya, peserta didik mulai terbiasa dengan nagham bayati dan kelihatan antusias bagi yang bisa mengikuti alur nagham bayati dalam pembelajaran. Bahkan sudah mulai ada yang berani memberikan contoh lagu pada temannya. Bagi siswa yang kurang bisa mengikuti tetap bisa mendengarkan dan berusaha untuk mengikuti (mulai beradaptasi). Tidak terlihat adanya anak yang kurang bersemangat, hampir semuanya termotivasi untuk bisa, dan bisa.

Penerapan metode alternatif dengan metode tilawah nagham bayati ternyata telah merubah suasana kelas menjadi hidup dan menarik untuk diikuti. Bacaan demi bacaan, lagu demi lagu mengalun bersama ayat-ayat al-Qur'an semakin ada rasa, semakin bisa dihayati dan bisa diresapi dalam sanubari siswa. Hasil wawancara menunjukkan adanya semangat dan motivasi untuk mengikuti pembelajaran dengan Qur'an Hadis dengan mampu membaca dengan baik dan benar, benar menurut kaidah ilmu tajwid serta baik dan indah untuk didengarkan, sesuai kaidah ilmu nagham.

Namun, sebuah implementasi metode pembelajaran tidaklah tanpa kekurangan.Masih adanya beberapa siswa yang merasa tidak bisa mengikuti lagu dan irama dari Nagham Bayati ini.Faktor yang utamanya adalah pada karakter suara peserta didik yang tidak semuanya mampu mengikuti irama dan nada bayati. Hal ini berdampak pada masih adanya peserta didik yang perlu perhatian dalam mengikuti proses pembelajaran.

\author{
MUBTADI: Jurnal Pendidikan Ibtidaiyah \\ Vol. 2 No. 2, Januari - Juni 2021 \\ $P$ - ISSN : 2715 - 7067 \\ E - ISSN : $2720-8850$
}


Selain itu, dengan terbatasnya durasi waktu dan materi pembelajaran, juga berdampak pada minimnya lagu atau nagham yang bisa dipelajari disetiap pertemuan. Dari hasil pengamatan dan wawancara dengan guru dan siswa, di dalam setiap pertemuan ternyata penerapan nagham belum maksimal, artinya perlu pengulangan-pengulangan yang lebih agar mampu tersimpan di memori secara benar. Walaupun terdapat beberapa siswa yang mempu menyerap secara cepat, namun tidak semuanya siswa seperti itu.

Walaupun terdapat beberapa kekurangan, akan tetapi tidak mengurangi esensi atau tujuan dari penggunaan metode tilawah yang dalam hal ini dengan Nagham Bayati dalam membangkitkan motivasi siswa untuk mengikuti pembelajaran Qur'an Hadis di madrasah.

\section{KESIMPULAN}

Kehadiran metode tilawah dengan ngham bayati telah merubah suasana kelas menjadi pembelajaran yang hidup dan menarik untuk diikuti peserta didik. Bacaan demi bacaan, lagu demi lagu berkumandang dari ayat-ayat al-Qur'an semakin ada rasa dan mulai bisa diresapi dalam hati siswa.Hasil wawancara menunjukkan adanya semangat dan motivasi untuk bisa membaca al-Qur'an dengan baik dan benar menurut kaidah ilmu tajwid serta indah dan bagus untuk didengarkan sesuai kaidah ilmu nagham atau metode tilawah.

Namun, efektifitas dari sebuah implementasi metode pembelajaran tidaklah tanpa kekurangan.Dengan terbatasnya durasi waktu dan materi pembelajaran juga berdampak minimnya lagu atau nagham tilawah yang bias dipelajari.Dari hasil pengamatan dan wawancara dengan guru dan siswa, di dalam setiap pertemuan ternyata penerapan nagham hanya pada nagham bayyati, yang merupakan satu dari tujuh macam nagham tilawah.Tetapi itu tidak mengurangi esensi atau tujuan dari penggunaan metode tilawah dalam membangkitkan motivasi siswa untuk mengikuti pembelajara Qur'an Hadis di madrasah.

Maka peneliti menyimpulkan bahwa, nagham bayati mampu meningkatkan motivasi siswa dalam mengikuti proses pembelajaran mata pelajaran Qur'an Hadis, dan dapat menjadi metode pembelajaran alternatif di madrasah. 
Saifus M̂Mujab

Nagham Bayati sebagai Alternatif Model Pembelgiaran Qur'an Hadis di Madrasah

Kelas Dasar

\section{DAFTAR PUSTAKA}

Al-Qur'an Al-Mahir, Madina Qur'an, Surakarta, 2016

Anselm Strauss \& Juliet Corbin, Basic of Qualitative Research : Grounded

Theory Procedures and Techniques, Terj. Muhammad Shodiq \& Imam Muttaqin

Yogyakarta: Pustaka Pelajar, 2003

Bimas Islam, Pedoman Pelatihan Tilawatil Qur'an, Jakarta, 1995

Hasan Usman danPurnomoSetiadi Akbar, MetodologiPenelitianSosial, Jakarta:

PT. BumiAksara, 2009

Lexy Moleong, Metodologi Penelitian Kualitatif, Bandung: Rosdakarya, 1995

Mujab Saiful, Ilmu Nagam, Kaidah Seni Baca al-Qur'an, Kudus, 2011

Nasution, Metode Research, Jakarta: Bumi Aksara, 2000

Nazir, Metode Penelitian, Jakarta: Ghalia Indonesia, 1983

Salim Muhsin, Ilmu Nagham al-Qur'an, Belajar Membaca al-Qur'an Dengan

Lagu, Yataqi, Jakarta, 2008

Suharsimi Arikunto, ProsedurPenelitianSuatuPendekatanPraktis, Jakarta:

RinekaCipta, 1998

Sukardi, MetodologiPenelitianPendidikandanPrakteknya, Yogyakarta:

BumiAksara, 2003

Sugiyono, MemahamiPenelitianKualitatif, Bandung: Alfabeta, 2010

Sugiyono, Metode Penelitian Pendidikan; Pendekatan Kuantitatif, Kualitatif dan

$R \& D$, Bandung: Alfabeta, 2006

Sutrisno, Tri. 2019. Pengaruh Pembelajaran Berbasis Masalah (Problem Based

Learning) Terhadap Kemampuan Berpikir Kritis Siswa pada Mata Pelajaran PKn

Kelas VI di SDN Kota Sumenep.ELSE (Elementary School Education Journal):

Jurnal Pendidikan dan Pembelajaran Sekolah Dasar. Volume 3 Jilid 2. Hal. 98-110

Sutrisno, Tri. 2014. Asupan Anak Melalui Konseling. Halaman Moeka

Publishing. Jakarta Barat

Zainal Arifin, Evaluasi Pembelajaran, Bakung: PT Remaja Rosdakarya, 2009 